\title{
Simulation of Temperature Rise in Li-ion Cells at Very High Currents
}

\author{
Jing Mao ${ }^{\mathrm{a}}$, William Tiedemann ${ }^{\mathrm{b}}$, and John Newman ${ }^{\mathrm{a}, \mathrm{c},}$ * \\ aEnvironmental Energy Technologies Division, Lawrence Berkeley National Laboratory, \\ Berkeley, CA 94720, USA

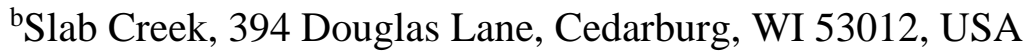 \\ 'Department of Chemical and Biomolecular Engineering, University of California, \\ Berkeley, CA 94720, USA \\ *Corresponding author: newman@ newman.cchem.berkeley.edu
}

\begin{abstract}
The Dualfoil model is used to simulate the electrochemical behavior and temperature rise for $\mathrm{MCMB} / \mathrm{LiCoO}_{2} \mathrm{Li}$-ion cells under a small constant-resistance load, approaching a short-circuit condition. Radial mass transport of lithium from the center of the pore to the pore wall has been added to the model to describe better current limitations at very high discharge currents. Electrolyte and solid-surface-concentration profiles of lithium ions across the cell at various times are developed and analyzed to explain the lithium-ion transport limitations. Sensitivity tests are conducted by changing solution and solid-state diffusion coefficients, and the heat-transfer coefficient. Because diffusion coefficients increase at high temperature, calculated discharge curves can show currents dropping initially but then rising to a second peak, with most of the
\end{abstract}


available capacity being consumed in the second peak. Conditions which lead to such a second peak are explored.

Keywords: Simulation; Lithium-ion cell; Thermal-electrochemical model; High-current discharge; Mass-transport limitation; Overheating

\section{Introduction}

Li-ion batteries are widely used in mobile technologies because of their high energy and power density. The usage extends from small cell phones to electric vehicles, and even to airplanes. With bigger batteries, more concern on battery safety is aroused. Reviews of thermal issues in Li-ion batteries point out that the safety problem results from thermal runaway causing fire and explosion, and it is clear that no existing thermal-management strategy or technology meets all these requirements $[1,2]$.

The key to battery safety is to manage the temperature properly. A battery can be safe under moderate operating condition (e.g., low current), but is compromised for larger cells and higher currents (low-resistance loads). The temperature rise of a $\mathrm{Li}$-ion cell is determined by heat produced internally and heat exchanging with the environment during operation, and can be predicted using a thermal-electrochemical-coupled model. The coupling of thermal and electrochemical models arises from temperature-dependent physicochemical properties and the heat-generation equation. The history of thermal-electrochemical-coupled models has been given in references [3, 4]. Internal 
and external short-circuit tests are routine for Li-ion-battery safety tests in industry, and high temperatures that result from extremely high discharge current are sometimes observed during short-circuit tests [5-8]. It is urgent to interpret the various experimental phenomena fundamentally by simulation. The goal of this work is to use the thermal-electrochemical-coupled Dualfoil model to simulate the temperature rise in Li-ion cells at very high currents and understand fundamentally the quick temperature rise to above $120^{\circ} \mathrm{C}$ during short-circuit tests.

The Dualfoil model is a powerful and flexible mathematical model that can be used to treat the coupled phenomena in a porous-electrode battery system (including Ni-MH and Li-ion batteries). It has six coupled differential equations (a material balance on the electrolyte, a material balance on the solid intercalant, Ohm's law in the liquid phase, Ohm's law in the solid phase, a current balance that relates the flow of current between the solid and liquid phases, and a Butler - Volmer kinetics expression) [9]. Review of the Dualfoil model and more detailed descriptions are given in reference [10-12]. A clear schematic of the Li-ion cell in Dualfoil modeling has been given in a recent reference [13]. Unlike other commercial simulation programs, such as COMSOL, MATLAB, the Dualfoil program based on Dualfoil model is open access, and can be downloaded from our website and has low computational demands [14]. The Dualfoil software employs Newman's BAND (j) subroutine, which is a finite-difference method 
(FDM) used to simulate electrochemical systems for more than four decades. The model has been improved over the years to include impedance $[15,16]$, a better thermal balance [17-21], additional battery chemistries [22-25], etc., and has more and more applications [13, 26-29]. When discharging under nonequilibrium conditions such as very high currents, the distribution of current, potential, and lithium concentration inside the porous electrode is nonuniform, leading to increased internal resistance, producing large heat, and thus increasing the cell temperature. The transport properties in the electrolyte and solid phases and the electrochemical reaction rate can be increased by temperature rise following some empirical relationship, and an Arrhenius exponential relationship is usually adopted. This temperature rise in turn will cause more current to pass the cell. This kind of positive feedback between temperature and those physicochemical properties can lead to overheating issues and must be dealt with [30]. Simulation can give deep insight into the internal behavior of batteries, and can provide information that is difficult or impossible to obtain by experiment [31]. A good review of model development and simulation of Li-ion cells at different length and time scales is given by reference 29 .

When simulating the thermal and electrochemical behavior of a Li-ion cell at abnormally large discharge currents, there are two difficult problems for the Dualfoil model. The first problem is that the salt concentration can be reduced substantially and 
even try to go negative locally when the discharge current is very high, and the Dualfoil program has shown a tendency to stop short of the full simulation due to lack of convergence. For a real electrolyte system, the local salt concentration cannot be zero or negative. This issue has always been present in the model, and various approximations have been developed to bypass the issue for a given set of conditions. In this work, we develop a radial mass-transport coefficient of solution diffusion to solve the convergence problem. Most previous porous-electrode models consider only mass transport along the pores and ignore radial transport in the pores. This means that the absence of a radial transport limitation allows even the most dilute solutions to support large currents. To address this issue, a radial mass-transport condition (i.e., limiting current) has been introduced into the model. With discharge at extremely high currents, the local salt concentration can only get very close to zero, and the transfer current will approach its limit. This modification to the Dualfoil model results in smooth operation and allows the program to run at virtually all currents, and dramatically reduces the running time. The model modification and derivation are presented in the next section.

The second problem is how to compute the variable solid diffusion for lithium ions with more accuracy and in short computational time. In this work, lithium ions are still assumed to diffuse radially in the spherical solid particle following Fick's laws; and with a solid diffusivity which does not vary, the concentration profile can be computed 
efficiently by the Duhamel superposition integral (which is an advanced mathematical method [32]) as done in the original Dualfoil model. There are many mathematical methods for treating solid diffusion in simulation research, and the usage of some approximate approaches for simulations of Li-ion solid transport in batteries is reviewed [33]. More detailed discussion of the advantages and disadvantages of using Duhamel superposition integral to compute with a variable solid diffusion is shown in a later section.

In this paper, the thermal-electrochemical model (Dualfoil) is used to simulate the electrochemical behavior and temperature rise for a $\mathrm{MCMB} / \mathrm{LiCoO}_{2}$ cell discharging under a constant-resistance load. A set of parameters is used in the base-case simulation for a small resistance load ( $\left.R_{\text {load }}\right)$ of $0.2 \times 10^{-3} \Omega \cdot \mathrm{m}^{2}$. Then sensitivity tests on some parameters are conducted and investigated. By looking at very high currents (approaching a short-circuit condition), we hope to learn more about parameters which can impact overheating in batteries.

\section{Model}

In the Dualfoil model, the six coupled differential equations are solved numerically and simultaneously at each time step. A summary of the equations is presented in Table $\mathrm{V}$ in the appendix; it is noted that only the kinetic equation is modified by a denominator. A function has been developed which describes the radial mass 
transport of lithium ions in the pore. Starting with the original kinetic B-V (Bulter-Volmer) equation in the model, ( $i$ is transfer current density, $j$ is transfer flux)

$$
i=j F=i_{0}\left[\exp \left(\frac{\alpha_{\mathrm{g}} F}{R T} \eta_{s}\right)-\exp \left(-\frac{\alpha_{\mathrm{c}} F}{R T} \eta_{s}\right)\right]
$$

insert a new term in front of the cathodic term

$$
i=j F=i_{0}\left[\exp \left(\frac{\alpha_{\mathrm{g}} F}{R T} \eta_{\mathrm{s}}\right)-\left(1-\frac{i}{i_{\lim }}\right) \exp \left(-\frac{\alpha_{\mathrm{c}} F}{R T} \eta_{\mathrm{s}}\right)\right]=\frac{\left[\exp \left(\frac{\alpha_{\mathrm{g}} F}{R T} \eta_{\mathrm{s}}\right)-\exp \left(-\frac{\alpha_{\mathrm{c}} F}{R T} \eta_{\mathrm{s}}\right)\right]_{\mathrm{o}}}{1-\frac{i_{\mathrm{o}}}{i_{\lim }} \exp \left(-\frac{\alpha_{\mathrm{C}} F}{R T} \eta_{\mathrm{s}}\right)}
$$

Physically this is intended to represent a term like $c_{0} / c_{\text {bulk }}=1-i / i_{\mathrm{lim}}$, where $i_{\mathrm{lim}}$ is proportional to the bulk or average concentration in the pore and can be calculated roughly by equation 3. $c$ is the average concentration already calculated by Dualfoil in the pores, and $r$ is the radius of the pore, which represents a diffusion-layer thickness and can only be estimated. At the cathode, the transfer current is negative, and $i$ lim should be negative.

$$
\left|i_{l i \mathrm{~m}}\right|=\frac{F c D}{r}
$$

The new term denominator is added in the new B-V equation as following,

$$
i=j F=i_{0}\left[\exp \left(\frac{\alpha_{\mathrm{g}} F}{R T} \eta_{\mathrm{s}}\right)-\exp \left(-\frac{\alpha_{\mathrm{c}} F}{R T} \eta_{\mathrm{s}}\right)\right] / \text { denominator }
$$

where

denominator $=1+\frac{\text { coef }}{c} \exp \left(-\frac{\alpha_{\mathrm{c}} F \eta_{\mathrm{s}}}{R T}\right)=1-\frac{i_{0}}{i_{\mathrm{lim}}} \exp \left(-\frac{\alpha_{\mathrm{c}} F}{R T} \eta_{\mathrm{s}}\right)$

and coef represents $-i_{0} /\left(i_{\mathrm{lim}} / c\right)$. As $i_{0}, i_{\mathrm{lim}}$ are all concentration dependent, and $i_{\mathrm{lim}}$ can only be estimated, we set coef as constant in the program to simplify this problem. 
This is not intended to be a rigorous addition to the program; it is designed to make convergence much easier while still being based on a physical concept. The exact value assigned to coef does not have a great significance in terms of the results. This idea provides a physically realistic modification to prevent driving the solution concentration locally to zero. Then the Dualfoil program is able to run smoothly and quickly under very-high-current discharges (in excess of $13000 \mathrm{~A} / \mathrm{m}^{2}$ ). As the solution concentration approaches zero in the pore, the mass transport is slowed down due to limited rates of radial diffusion. The mass transfer is not infinite but approaches a limit, and the transfer current $i$ approaches the limiting current $(i \mathrm{lim})$. With $r=5 \times 10^{-6} \mathrm{~m}, c=0.01 \mathrm{~mol} / \mathrm{m}^{3}$, and $D=2.0 \times 10^{-10} \mathrm{~m}^{2} / \mathrm{s}, i_{\text {lim }}$ is calculated as $0.04 \mathrm{~A} / \mathrm{m}^{2}$. By changing coef in the model, the transfer current in the back of positive electrode should be approaching $i_{\text {lim. }}$. Intensive simulation results indicate that coef $\leq 1 \mathrm{~mol} / \mathrm{m}^{3}$ can achieve the goal. In the following simulations, coef is set to $1 \mathrm{~mol} / \mathrm{m}^{3}$. To see more details on this modification (denominator, coef), one can explore the latest version of Dualfoil program on our website [14].

\section{Model parameters}

For the model based on fundamental laws of transport, kinetics, and thermodynamics, many physical properties, as well as the geometry of the cell, are required. The parameters used in the base case are listed in Tables I to IV. The limit 
on number of iterations is set to a relatively large number so that convergence can be achieved on a zero-time step. The numbers of nodes in the negative electrode, separator, positive electrode, and solid particle are set to be $40,40,80$, and 100 . The discharge cutoff potential is $0.0001 \mathrm{~V}$. The resistance load is very small, that is, $R_{\text {load }}=0.0002$ $\Omega \cdot \mathrm{m}^{2}$.

In this paper, we use the simple one-dimensional (1D) thermal and electrochemical model for one sandwich cell, the detail of the heat conduction within the cell are not discussed, and the temperature distribution in the cell is assumed to be uniform. Only the heat dissipated to the surroundings from the cell surface is considered. This simplification is realistic and reasonable for relatively small cells of elongated geometry which have a high aspect ratio, such as a prismatic cell with stacked layers, or a cylindrical cell having spirally wound layers.

The heat capacity, $C_{p}$, is estimated to be $1000 \mathrm{~J} / \mathrm{kg} \cdot \mathrm{K}$, including all the cell materials $[4,34] . \quad$ The capacity ratio of negative/positive electrode is 1.56 . The cell is positive limited, and its capacity is calculated to be $17.6 \mathrm{Ah} / \mathrm{m}^{2}$ based on the $\mathrm{LiCoO}_{2}$ electrode. In the base case, $0.368 \mathrm{~W} / \mathrm{m}^{2} \cdot \mathrm{K}$ is used for $h$ to represent a disadvantageous heat-transfer condition [35]. Grid resistance $(R G)[36]$ is added in the Dualfoil program, which includes the total resistance in foils, leads, and contacts of the cell, and is a large component of internal cell resistance. Typical internal resistance is in the order of 
milliohms. For the base-case simulation, $R G$ is set to be $0.8 \times 10^{-3} \Omega \cdot \mathrm{m}^{2}$, and $R G_{\text {ext }}$ is set to be $0.2 \times 10^{-3} \Omega \cdot \mathrm{m}^{2}$. $R G_{\text {ext }}$ is the grid resistance outside the cell sandwich (but not $R_{\text {load}) .}$

Matrix conductivity is assumed to be high value, and film resistance reflects the resistance of SEI layer on the anode [24]. The exchange current density $\left(i_{0}\right)$ depends on the local instantaneous concentrations as computed in the program.

$$
i_{0}=F k c^{\alpha_{\mathrm{a}}}\left(c_{\mathrm{t}}-c_{\mathrm{g}}\right)^{\alpha_{\mathrm{c}}} c_{\mathrm{s}}^{\alpha_{\mathrm{a}}}
$$

In some simulation literature, only initial exchange current density values are given, without the rate constant $(k)$. Here we not only show $k$, but also calculate $i 0$ value for the readers' convenience. The values of reaction rate constants are set to be relatively high, and the two insertion-electrode reaction kinetics are assumed to be facile, and thus not the limiting step. The exchange current varies with concentration, and we can calculate with one composition as an example. When $c=1000 \mathrm{~mol} / \mathrm{m}^{3}$, the calculated exchange current density $\left(i_{0}\right)$ at $298 \mathrm{~K}$ for $\mathrm{Li}_{0 .} \mathrm{C}_{6}$ and $\mathrm{Li}_{0.6} \mathrm{CoO}_{2}$ by Equation 6 is 110 and $220 \mathrm{~A} / \mathrm{m}^{2}$, respectively. Compared with values used in other references, these values are relatively high. The densities in Table II are crystalline values as reported in the literature [37].

The temperature of the cell can be calculated by an energy balance $[19,20,38]$,

$$
-\int_{v} \sum_{l} i_{n_{l} l} U_{H_{l} l} d v-I V-I^{2} R G_{\mathrm{ext}}=M C_{p} \frac{d T}{d t}+h\left(T-T_{\mathrm{a}}\right),
$$


and the heat produced by the external grid resistance $\left(R G_{\mathrm{ext}}\right)$ has been deducted. $U_{\mathrm{H}}$ is the enthalpy potential and can be calculated by: $U_{\mathrm{H}}=U-T d U / d T$. The relations of $U$ (open-circuit potential) and $d U / d T$ with lithium concentration for $\mathrm{Li}_{y} \mathrm{CoO}_{2}$ and $\mathrm{MCMB}$ $\left(\mathrm{Li}_{x} \mathrm{C}_{6}\right)$ electrodes [38] are displayed in the Appendix.

The Dualfoil program has been developed for many years and various electrolyte systems been put in the program according to our research $[39,40]$. For the state-of-art lithium ion battery, the most common electrolyte system is alkyl carbonate based, and the Li-ion battery industry does not have as many choices for electrolyte as there are for positive materials. Here the commonly used Bruggeman expression $\left(\varepsilon^{1.5}\right)$ is used to correct the salt diffusion coefficient and ionic conductivity for the base-case simulation. The lithium-ion transference number and thermodynamic factor are set to be constant. There are other studies on electrolyte [41-43].

To realize fully thermal-electrochemical coupling, the dependence of physical properties on temperature must be considered. We assume an Arrhenius-type relationship

$$
\Psi=\Psi_{0} \exp \left[\frac{E a(T-298)}{298 R T}\right]
$$

between the physical properties ( $\Psi_{0}$ represents $D, k, \kappa, D_{\mathrm{s}}, R_{\mathrm{f}}$ at $298 \mathrm{~K}$ ) and temperature. Due to lack of abundance of direct experimental data [35, 42, 44-47], these activation-energy values are assumed based on classical textbooks [48-52]. 


\section{Results and discussions}

\subsection{Superposition integral and variable $D_{\mathrm{s}}$}

A difficult problem in modeling research existing for many years is how to simulate a variable solid diffusivity $\left(D_{\mathrm{s}}\right)$ not only based on physics and experimental property measurements but also in a short time. Efforts in numerical methods have been summarized by Ramadesigan et al. [53] and Zeng et al. [54]. Although we know that $D_{\text {s }}$ varies with concentration and temperature by experiments, an effective mathematical method is still needed to treat variable $D_{\text {s }}$ approximately and obtain simulation results in acceptable accuracy.

The Dualfoil model has two modes of computation, and we can set mvdc1 or mvdc3 as 1 in the input file to run the program with variable $D_{\text {s }}$ ( see introduction to Dualfoil on our website) [14]. When $D_{\text {s }}$ does not vary (over time and position, and hence over temperature and composition), it is appropriate to use a Duhamel superposition integral. This saves greatly in computation time. If $D_{\mathrm{s}}$ varies, it is proper to use a finite-difference treatment in the solid particles. This is much slower, and it can run into convergence problems. We elected to use the faster and more robust superposition integral to compute variable $D_{\mathrm{s}}$, and in practice we find this method gives good results. This approximate approach is also adopted by other researchers to get rapid simulation [55]. 
Figure 1 gives an idea of the error incurred. It shows current and temperature calculated with the superposition method (curves a and b, which go out to greater capacity) and the more accurate finite-difference method (curve c, which fails earlier). When the activation energies for $D_{\text {s }}$ are zero, there is less actual variation of $D_{\mathrm{s}}$, and the superposition method should become comparable in accuracy to the finite-difference method. Figure 1 compares the three numerical modes. The original Dualfoil4.2 model using the Duhamel superposition integral is strictly valid only for dealing with constant $D_{\text {s }}$ (case a). Dualfoil5.0 model adds a pseudo-2D procedure to deal with variable $D_{\text {s }}$ (case c), but it takes longer and may not converge. Figure 1 indicates how large an error one might expect when using superposition (case b) as an approximation with variable $D_{\text {s, }}$ as compared with case c. A special set of parameters and constant current mode are adopted to get as much data for case c (long simulation time) and give readers visualized comparisons between the three numerical modes. To get faster but converged results, in the following simulations we use the superposition method to treat with variable negative and positive $D_{\text {s }}$ for the modeling purpose of very-high-current discharge mode with an appropriate accuracy, reducing the simulation time of this spherical diffusion process effectively for large-scale simulations. A typical discharge of the cell under constant resistance is simulated in less than 20 min using this approximation. 


\subsection{Base-case Simulation}

The simulated results of current and temperature-rise behavior for case I (base case) and case II are shown in Figure 2a and 2b. The in-depth analysis of the two cases is shown in Figure 3a to 3f. Case $\mathrm{I}$ is the base case, and solution diffusivity $(D)$ is dependent on temperature with an activation energy $(E a)$ of $16.6 \mathrm{~kJ} / \mathrm{mol}$ (as shown in Table IV). For comparison, we change only one parameter of the base case, turning off the thermal activation of $D$, which is case II. Case II is the situation that solution diffusivity $(D)$ is independent on temperature, with zero activation energy, maintaining the $D$ value at $298 \mathrm{~K}$, but still including the composition dependence shown in Table III.

The simulated results in Figure $2 \mathrm{a}$ and $2 \mathrm{~b}$ for the two cases are very different. This is due to the difference of thermal-electrochemical coupling effect and the difference of solution diffusion coefficient $(D)$. For both cases, the zero-time peak current is controlled by the sum of the resistance of the external load and the effective resistance of the electrochemical cell. The current distribution within the porous electrodes is controlled by the electrode kinetics and the conductivities of the solution and solid phases $[56,57]$. For times larger than zero, the current initially declines rapidly due to mass-transport limitations of lithium ions in solution and the rise in surface concentration of lithium on the positive electrode surface (see Figure 3). The negative electrode is not 
showing significant limiting behavior characteristics since the lithium-ion concentration is rising within the porous electrode.

For the base case, as temperature rises, the solution and solid-state diffusion coefficients begin to rise, resulting in improved mass transport of lithium in the solution and solid phases leading to a reversal of the decline in current. The current continues to increase as mass transport increases. During this period, the lithium ion concentration in the solution increases while the surface concentration of lithium begins to approach unity along the length of the pore. When the peak in the current is reached, mass transport of lithium into the solid particle becomes limiting (the surface concentration is beginning to approach the maximum concentration of particle), and the current begins a continuous decline over a period of minutes. The current plot shows a sharp peak after the quick drop, and the cutoff potential $(0.0001 \mathrm{~V})$ for simulation is reached rapidly. The current has its maximum value of $2514 \mathrm{~A} / \mathrm{m}^{2}$ at the beginning of discharge (point $\mathrm{b}$, $i_{\max }$ ), drops sharply to the valley value of $823.3 \mathrm{~A} / \mathrm{m}^{2}$ (point $\mathrm{c}, i_{\text {valley }}$ ), climbs to the sharp peak value of $1932 \mathrm{~A} / \mathrm{m}^{2}$ (point $\mathrm{e}, i_{\text {peak) }}$ ), and then decreases gradually to near zero. However, for case II, due to no thermal activation of the solution diffusion coefficient, the solution limitation has no chance to decrease, and the second sharp peak disappears; the current shows a gentle slope after the rapid drop to $300 \mathrm{~A} / \mathrm{m}^{2}$, and the cutoff potential 
is reached in a longer time. The cell temperature rises more rapidly for the base case, reaching $120^{\circ} \mathrm{C}$ in $12 \mathrm{~s}$, while the cell temperature reaches $120^{\circ} \mathrm{C}$ in $27 \mathrm{~s}$ for case II.

As shown in Figure 2b, for the same utilization, the base case shows a lower cell temperature rise than case II due to its lower solution mass-transport limitation; for the same discharge time, the base case shows a higher utilization (a faster discharge). For the base case, most of the capacity is given out at the sharp peak; the average utilization of positive material reaches 0.6 at $30.5 \mathrm{~s}$. For case II, most capacity is given out at the gentle slope; the average utilization of positive material reaches only 0.23 at $30.5 \mathrm{~s}$. The temperature-rise rate is approximately proportional to the discharge capacity (or utilization of the positive material) for both cases. The reason for higher maximum temperature for case II is that the utilization is higher.

Heat can be produced by electrochemical reaction, chemical side reactions, and Joule heating inside the battery. In these simulations, chemical side reactions are not considered, and only the normal electrochemical reaction is included. At the starting moment of discharge, the internal cell resistance is composed of $R G\left(0.8 \times 10^{-3} \Omega \cdot \mathrm{m}^{2}\right)$, other solid and solution ohmic resistance, and electrochemical-kinetic resistance; the load resistance is $0.2 \times 10^{-3} \Omega \cdot \mathrm{m}^{2}$; Uocp is about $3.8 \mathrm{~V}$; and thus the current density is very high (more than $2500 \mathrm{~A} / \mathrm{m}^{2}$ ), and Joule heat $\left(Q=i^{2} R t\right)$ is dominant. The cell temperature rises quickly to more than $50^{\circ} \mathrm{C}$ at $4.2 \mathrm{~s}$ for both cases. The quick drop of 
current for both cases results from the solution mass-transport limitation; the high current certainly depletes the solution in the back of the positive, and the surface of the active material in the front of the positive becomes nearly saturated. The solution mass-transport resistance is dominant.

To understand better the difference between base case and case II, the solution concentration profiles are simulated and shown in Figure $3 \mathrm{a}$ and $3 \mathrm{~b}$. For the base case, thanks to the thermal activation of $D$, the solution gradients decrease gradually, the solution then becomes more and more uniform, and the solution limitation disappears finally at point $f$. That is the reason for the sharp current peak appearing. But for case II, without thermal activation of $D$, the solution mass transfer has no chance to increase. The solution gradients stay large, and the solution limitation exists all the time. That's why the current declines at a gentle slope. When solution limitations appear, the solution mass-transport resistance will be large, which can account for the quick drop at $4.20 \mathrm{~s}$ for both cases.

As shown in Figure $3 \mathrm{c}$ and $3 \mathrm{~d}$, for both cases at $4.2 \mathrm{~s}$, the solid surface concentration in the front of the positive electrode reaches near saturation ( $y$ approaches 1) due to high electrolyte concentration and favorable potential near the separator; the solid surface concentration in the back of positive electrode is much smaller due to the low electrolyte concentration and unfavorable potential. As the solid surface concentration 
nears saturation, the solid diffusivity is also a limitation for both cases. For example, as for the base case at $30.5 \mathrm{~s}$, the solution concentration is uniform (solution-mass transport limitation disappears) due to the thermal-electrochemical coupling effect; the $y$ value in the $\mathrm{Li}_{y} \mathrm{CoO}_{2}$ surface is more than 0.98 (nearly saturated), but the average $y$ value through the whole positive electrode is only 0.8362 , which means that the core of the solid particle still has a lot of vacancies for lithium ions, and the discharge is controlled by lithium ions diffusing from the surface into the core.

According to the Butler-Volmer equation, transfer current $j$ is determined by solution concentration, solid surface concentration, and overpotential. Figure $3 \mathrm{e}$ and $3 \mathrm{f}$ show the distribution of transfer current across the positive electrode. For both cases, at the front of the positive electrode, a solution limitation does not exist, the solid surface approaches saturation, and transfer current shows a constant value, indicating a steady discharge state controlled by solid diffusion. For the base case, due to the temperature rise and increase of $D$ and $D_{s}$, the electrolyte diffuses to the back of the positive electrode gradually, and the transfer current increases. At $30.5 \mathrm{~s}$, the transfer current is uniform and almost constant. For case II, at $30.5 \mathrm{~s}$, the transfer current at the back of the positive electrode is still very small. This is because the solution concentration is still near zero, lacking the thermal activation of $D$. But for case II, from point $\mathrm{c}$ to $\mathrm{f}$, the transfer 
current shows the trend of becoming more uniform; this must be due to the thermal activation of solid diffusion, increasing $D_{\text {s. }}$

From the above discussion, it is found that the temperature dependence of $D$ has a large impact on the discharge behavior. Therefore, we calculated the diffusion coefficient by Equation 8. For the base case, from point $\mathrm{c}$ to e, the temperature varies from 65.5 to $185.38^{\circ} \mathrm{C} ; D_{\mathrm{s}, \mathrm{p}}$ is doubled, and $D$ is increased to 4.5 times

\subsection{Simulation of sensitivity tests}

In the following, a series of sensitivity tests is conducted to investigate the effect of each parameter on the cell temperature. Without doing expensive and dangerous battery safety tests [58], with the help of numerical simulations, we can explore the cell performance in a wide range, obtain deep understanding of overheating inside the cell, and interpret many experimental phenomena.

Mass-transport resistance is a large source of internal resistance determining the heat production. Firstly, we change parameters related to solution mass transport. Secondly, we change parameters related to solid mass transport. Then, we change parameters related to heat transfer to the environment.

The main feature of the lithium ion battery is its porous structure. Electrolyte diffuses inside the pores (a limited space) formed by solid material. The effective values of transport properties ( $D_{\text {eff }}$ and $\kappa_{\text {eff }}$ ) in porous electrodes are smaller than the 
intrinsic value which is measured in a free solution. The Bruggeman relation (Equation 9) is often used to calculate the effective value.

$$
D_{\text {eff }}=D \varepsilon^{\alpha}
$$

The porous networks of negative electrode, positive electrode, and separator are different.

In the Dualfoil model, the Bruggeman exponent $(\alpha)$ is now set separately for the negative electrode (Exbrug1), the separator (Exbrug2), and the positive electrode (Exbrug3). The Bruggeman exponent has been shown to range from 1.5 to 3 from the information in the literature and from other battery systems [59]. In the base case, Exbrug $1=$ Exbrug $2=$ Exbrug3 $=1.5$. (In reference 12, a factor of $\varepsilon$ is taken out already for $D$, and the exponent would then be 0.5 instead of 1.5. In Dualfoil, a definition like Equation 9 is used for $D_{\text {eff }}$ as well as $\kappa_{\text {eff. }}$ )

Figure $4 \mathrm{a}$ indicates that decreasing the positive electrode porosity increases the valley current, and the sharp peak appears later. Figure $4 \mathrm{~b}$ indicates that increasing Exbrug3 decreases the valley current, and the sharp peak appears later with a smaller peak current. For a real battery, the porosity can vary over only a narrow range, but the Bruggeman exponent can be varied over a wide range due to material morphology [59]. Compared with the porosity, the Bruggeman exponent has a larger effect on $\kappa$ and $D$.

The solid-diffusion process inside the particles is determined by $D_{\mathrm{s}, \mathrm{p}}$ and $r_{\mathrm{p}}$. Many parameters such as doping element, lattice defects, lithium concentration, particle 
morphology, and electrode microstructure can affect the effective solid-diffusion coefficient of $\mathrm{Li}_{y} \mathrm{CoO}_{2}$ particles in the porous electrode. For simplicity, in this simulation, $D_{\mathrm{s}, \mathrm{p}}$ at $25^{\circ} \mathrm{C}$ is assumed to be the effective value and is adjustable. The diffusion distance for lithium ions inside the positive spherical particle is the radius $\left(r_{\mathrm{p}}\right)$, which can be adjustable in a wide range. Figure 5a shows that decreasing $D_{\mathrm{s}, \mathrm{p}}$ low enough causes the current peak to disappear; the temperature rising rate and the maximum temperature is decreased substantially. Figure $5 \mathrm{~b}$ shows that increasing the radius of $\mathrm{Li}_{y} \mathrm{CoO}_{2}$ particles causes the current peak and the cell temperature to decrease gradually. If the $\mathrm{Li}_{y} \mathrm{CoO}_{2}$ particle is big enough, the current peak will disappear too, and the cell temperature will be below $120^{\circ} \mathrm{C}$. Figure $5 \mathrm{c}$ shows the current peak of a series of sensitivity tests on combinations of $D_{\mathrm{s}, \mathrm{p}}$ and $r_{\mathrm{p}}$. (The temperature rise behavior is not shown here.) The red line is the boundary for peak and no peak. For very large particles and very low $D_{\mathrm{s}, \mathrm{p}}$, the $\mathrm{Li}_{y} \mathrm{CoO}_{2}$ surface should be saturated rapidly during the high-current discharge, and then the discharge is controlled by solid diffusion with a small transfer current. There should be no current peak, and the cell temperature will not rise to more than $120^{\circ} \mathrm{C}$, and no thermal runaway should happen. The behavior is similar to the effect of $D$, where shutting off the thermal activation of solution diffusivity causes the peak to disappear (see Figure 2). Through extensive simulations, we can understand many experimental results for short-circuit tests and that some high-power 
type Li-ion batteries, which commonly have smaller particles, show a higher possibility of overheating during nail penetration tests [5-7].

Under the same heat-transfer conditions, the temperature-rise rate for current-peak appearance is higher than that for no current-peak appearance. By choosing the proper electrode material and battery design, the cell temperature-rise rate under very high current discharge can be decreased a little.

A cell consisting of only one positive, negative, and separator and with external turbulent air flow might correspond to a heat-transfer coefficient of $36.8 \mathrm{~W} / \mathrm{m}^{2} \cdot \mathrm{K}$. A cell with a few more electrodes and free convection on the outside might correspond to $3.68 \mathrm{~W} / \mathrm{m}^{2} \cdot \mathrm{K}$. For a larger, perhaps spirally wound cell, a value of $0.368 \mathrm{~W} / \mathrm{m}^{2} \cdot \mathrm{K}$ might give a better representation of the average temperature, which can be substantially higher toward the core of the cell. With higher $h$, heat can go out of the cell faster; then the temperature-rise rate decreases, the maximum cell temperature decreases, and the peak current recovered by thermal activation will decrease, and even disappear.

Note that the maximum cell temperature is only $94.6^{\circ} \mathrm{C}$ for $h$ of $36.8 \mathrm{~W} / \mathrm{m}^{2} \cdot \mathrm{K}$, a very small value compared with that for small $h$. Because the solution and solid-diffusion limitations always exist under very-high-current discharge, the heat produced by internal resistance (mainly mass-transport resistance) is large. If the heat cannot be dissipated rapidly (small $h$ ), the thermal-electrochemical coupling effect will 
speed up the discharge process; the full capacity will be released rapidly and cause the cell temperature to reach $120^{\circ} \mathrm{C}$ more rapidly.

The simulation results for different $h$ values tell us that it is effective to decrease the cell temperature by increasing the heat-transfer coefficient. For a large and thick lithium-ion battery, the outer side of the cell has a big $h$, but the center of the cell has a small $h$. Heat is hard to dissipate from the center of the cell. For a lithium-ion battery used in electric vehicles, forced-convection cooling conditions should be very helpful to decrease the surface temperature of the cell. But we still need proper battery design to dissipate heat from the center of the cell effectively.

\subsection{Shut-down separator and side reactions}

To prevent the cell temperature from reaching elevated values observed in commercial cells and shown in Figure 7, a "shut-down" separator is used in which the pores begin to close when the temperature approaches approximately $127^{\circ} \mathrm{C}$. The commonly used separator is composed of a porous poly(ethylene) (PE)-polypropylene (PP) bilayer or a PP-PE-PP trilayer structure, which can shut itself down by closing the pores when the cell temperature is higher than the melting point of $\mathrm{PE}$ (about $127^{\circ} \mathrm{C}$ ) [60]. After the shut-down, lithium-ions cannot pass through the pores to reach the cathode, and the normal electrochemical discharge process stops. However, should the heating rate become large [60], closure of the pores may not be fast enough and the temperature may 
increase beyond the shut-down rated value (measured at $1{ }^{\circ} \mathrm{C} / \mathrm{s}$ ) before the pores are sufficiently closed to terminate the flow of current. Figure 7 shows that the simulated behavior of the cell has an associated heating rate $>60^{\circ} \mathrm{C} / \mathrm{s}$. This condition suggests that the temperature can easily reach temperatures exceeding $127^{\circ} \mathrm{C}$. This condition will result in accelerated heat generation caused by elevated rates of side reactions [61]. Under this condition the possibility of a thermal runaway can occur.

Side reactions are increased by rapidly rising temperatures. If heat generation exceeds that can be removed from the cell, the temperature will continue to rise. The lithium ion cell can perform well under moderate temperature and current density only because the kinetics of any side reaction is slow due to the formation of a solid-electrolyte interphase (SEI) [62-67]. The side reactions of Li-ion cells reported in the literature include the SEI film growing and decomposing on carbon negative material, solvent reduction, and decomposition of positive material, salt decomposition, and fracture of positive and negative solid material; continued rise in temperature results in a cell-pressure increase from a rise in vapor pressure and gas released by side reactions [68-70]. If the pressure becomes too high, a pressure-relief valve will be activated [71]. Even if the separator is shut down, and the normal discharge is stopped, some side reactions still can happen in the negative or positive electrode domains [72, 73]. More novel ideas such as thermo-responsive polymer added in the anode to aid shutdown are 
needed to improve battery safety [74]. The simulation of combining the shutdown separator and the side reactions for lithium-ion cell by the Dualfoil model is being studied now and will be reported in the future.

\section{Conclusions}

With a radial mass-transport coefficient to modify the thermal-electrochemicalcoupled Dualfoil model, simulation of very-high-current discharge of a lithium-ion cell is achieved. This modification not only allows the program to run at virtually all currents, but it also dramatically reduces the running time, allowing for timely exploration of the impact of changes in the various cell parameters. For small-resistance-load discharge, the current is high, and the cell temperature rise is large. The solution concentration in the back of the positive electrode becomes quite small, and the front of the positive becomes saturated with lithium at the surface of the particles. The current drops because it is now limited by diffusion within the particles at the front of the electrode. Under certain circumstances, this drop in cell potential and current occurs even though there is a lot of capacity in the back of the positive and some remaining at the center of the particles near the separator. Meanwhile, the large rise in cell temperature leads to an increase in the diffusion coefficients both in the solution and in the particles, and there is a dramatic increase in cell potential and current, permitting the rest of the cell capacity to be discharged rapidly. Sensitivity tests indicate that Li-ion cells composed of small 
particles with large effective solid diffusivity show more rapid temperature rise under high-current discharge. Special battery design is needed to achieve effective heat transfer outside the cell center and control the cell temperature in a proper range. An effective mechanism needs to be developed to shut down the exothermic side reaction inside the cell completely when the cell is overheating.

\section{Acknowledgments}

This work was supported by the Assistant Secretary for Energy Efficiency and Renewable Energy, Office of Vehicle Technologies of the U.S. Department of Energy under the Batteries for Advanced Transportation Technologies (BATT) Program.

\section{Appendix}

The equations used in the Dualfoil model are listed in table V. The open-circuit potential $d U / d T$ profiles used in the simulations are based on the results from references $[38,75,76]$ modified slightly, and displayed in Figure 8 . The fitting expressions are presented in Equation 10 to 13.

For the positive $\mathrm{Li}_{y} \mathrm{CoO}_{2}$ electrode

$$
\begin{aligned}
& U_{y}=2.16216+0.07645 \tanh (30.834-54.4806 y)+2.1581 \tanh (52.294-50.294 y) \\
& -0.14169 \tanh (11.0923-19.8543 y)+0.2051 \tanh (1.4684-5.4888 y) \\
& +0.2531 \tanh \left(\frac{-y+0.56478}{0.1316}\right)-0.02167 \tanh \left(\frac{y-0.525}{0.006}\right) \\
& \frac{d U_{y}}{d T}=\frac{-0.19952+0.92837 y-1.36455 y^{2}+0.61154 y^{2}}{1-5.66148 y+11.47636 y^{2}-9.82431 y^{2}+3.04876 y^{4}}
\end{aligned}
$$

For the negative $\mathrm{Li}_{x} \mathrm{C}_{6}(\mathrm{MCMB})$ electrode 


$$
\begin{aligned}
& U_{x}=0.194+1.5 \mathrm{e}^{[-120,0 x)}+0.0351 \tanh \frac{x-0.286}{0.083}-0.0045 \tanh \frac{x-0.849}{0.119}-0.035 \tanh \frac{x-0.9233}{0.05} \\
& -0.0147 \tanh \frac{x-0.5}{0.034}-0.102 \tanh \frac{x-0.194}{0.142}-0.022 \tanh \frac{x-0.9}{0.0164}-0.011 \tanh \frac{x-0.124}{0.0226} \\
& +0.0155 \tanh \frac{x-0.105}{0.029} \\
& \frac{d U_{x}}{d T}=\frac{A}{B} \\
& \mathrm{~A}=0.00527+3.29927 x-91.79326 x^{2}+1004.91101 x^{3}-5812.27813 x^{4}+19329.75490 x^{5} \\
& -37147.89470 x^{6}+38379.18127 x^{7}-16515.05308 x^{8}
\end{aligned}
$$

\section{List of Symbols}

$a$, active interfacial area per unit electrode volume, $\mathrm{m}^{-1}$

$C_{p}$, heat capacity, $\mathrm{J} / \mathrm{kg} \cdot \mathrm{K}$

$c$, electrolyte concentration, $\mathrm{mol} / \mathrm{m}^{3}$

$c_{0}$, electrolyte concentration at the electrode surface, $\mathrm{mol} / \mathrm{m}^{3}$

$c_{\mathrm{s}}$, lithium ion concentration in solid, $\mathrm{mol} / \mathrm{m}^{3}$

$c_{\mathrm{t}}$, maximum lithium ion concentration in solid, $\mathrm{mol} / \mathrm{m}^{3}$

$D$, bulk electrolyte diffusion coefficient, $\mathrm{m}^{2} / \mathrm{s}$

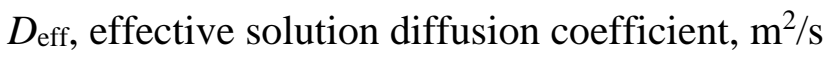

$D_{\mathrm{s}}$, solid diffusion coefficient, $\mathrm{m}^{2} / \mathrm{s}$

$D_{\mathrm{s}, \mathrm{p}}$, solid diffusion coefficient of positive electrode, $\mathrm{m}^{2} / \mathrm{s}$

$E_{a}$, activation energy, $\mathrm{J} / \mathrm{mol}$

$F$, Faraday's constant, $97485 \mathrm{C} / \mathrm{mol}$ 
$f_{ \pm}$, salt activity coefficient

$h$, heat transfer coefficient, $\mathrm{W} / \mathrm{m}^{2} \cdot \mathrm{K}$

I, cell-sandwich current density, $\mathrm{A} / \mathrm{m}^{2}$

$i$, transfer current, $\mathrm{A} / \mathrm{m}^{2}$

$i$, solid-phase current density, $\mathrm{A} / \mathrm{m}^{2}$

$i_{2}$, solution-phase current density, $\mathrm{A} / \mathrm{m}^{2}$

$i_{0}$, exchange current density, $\mathrm{A} / \mathrm{m}^{2}$

$i_{\text {lim, limiting transfer current, } \mathrm{A} / \mathrm{m}^{2}}$

$i_{n, l}$, transfer current at the node $(n, l), \mathrm{A} / \mathrm{m}^{2}$

$j$, transfer flux, $\mathrm{mol} / \mathrm{m}^{2} . \mathrm{s}$

$k$, insertion reaction constant, $\mathrm{m}^{2.5} \mathrm{~mol}^{-0.5} \mathrm{~s}^{-1}$

$M$, mass density of cell, $\mathrm{kg} / \mathrm{m}^{2}$

$R$, gas constant, $8.314 \mathrm{~J} / \mathrm{mol} \cdot \mathrm{K}$

$r$, radius of the pore, $\mathrm{m}$

$r_{p}$, radius of the positive electrode, $\mathrm{m}$

$R_{\mathrm{f}}$, film resistance $\Omega \cdot \mathrm{m}^{2}$

$\mathrm{T}$, cell temperature

$T_{\mathrm{a}}$, ambient air temperature, $\mathrm{K}$

$U$, open-circuit potential, $\mathrm{V}$ 
$U_{H}$, enthalpy potential, $\mathrm{V}$

$v$, volume of electrode

$x_{0}$, Initial stoichiometric value for $\mathrm{Li}_{x} \mathrm{C}_{6}$

$y_{\mathrm{o}}$, Initial stoichiometric value for $\mathrm{Li}_{y} \mathrm{CoO}_{2}$

$\alpha$, Bruggeman exponent

$\alpha_{a}$, anodic transfer coefficient

$\alpha_{c}$, cathodic transfer coefficient

$\varepsilon$, electrode porosity or volume fraction of solution

$\varepsilon \mathrm{f}$, volume fraction of inert filler

$\kappa$, ionic conductivity, $\mathrm{S} / \mathrm{m}$

$\eta_{\mathrm{s}}$, surface over-potential, $\mathrm{V}$

$\sigma$, electronic conductivity, $\mathrm{S} / \mathrm{m}$

$\Psi$, temperature-dependent physical properties

$\Psi_{0}$, temperature-dependent physical properties at $298 \mathrm{~K}$

\section{References}

[1] T.M. Bandhauer, S. Garimella, T.F. Fuller, J. Electrochem. Soc., 158 (2011) R1-R25.

[2] Q.S. Wang, P. Ping, X.J. Zhao, G.Q. Chu, J.H. Sun, C.H. Chen, J. Power Sources, 208 (2012) 210-224. 
[3] U.S. Kim, J. Yi, C.B. Shin, T. Han, S. Park, J. Electrochem. Soc., 160 (2013) A990-A995.

[4] N. Nieto, L. Diaz, J. Gastelurrutia, I. Alava, F. Blanco, J.C. Ramos, A. Rivas, J. Electrochem. Soc., 160 (2013) A212-A217.

[5] C. Kallfab, C. Hoch, A. Hilger, I. Manke, Proc. International Multi-conference on Systems, Signals and Devices, 2012, pp. 1-5.

[6] T. Yamauchi, K. Mizushima, Y. Satoh, S. Yamada, J. Power Sources, 136 (2004) 99-107.

[7] H. Maleki, J.N. Howard, J. Power Sources, 191 (2009) 568-574.

[8] S. Santhanagopalan, P. Ramadass, J. Zhang, J. Power Sources, 194 (2009) 550-557.

[9] M. Doyle, T.F. Fuller, J. Newman, J. Electrochem. Soc., 140 (1993) 1526-1533.

[10] K.E. Thomas, R.M. Darling, J. Newman, in: W.v. Schalkwijk, B. Scrosati (Eds.) Advances in Lithium-Ion Batteries, Kluwer Academic Publishers, New York, 2002.

[11] J. Newman, K.E. Thomas, H. Hafezi, D.R. Wheeler, J. Power Sources, 119 (2003) 838-843.

[12] J. Newman, K.E. Thomas-Alyea, Electrochemical Systems (third edition), John Wiley \& Sons Inc., Hoboken, New Jersey, 2004.

[13] J. Christensen, D. Cook, P. Albertus, J. Electrochem. Soc., 160 (2013) A2258-A2267. 
[14] http://www.cchem.berkeley.edu/jsngrp/

[15] M. Doyle, J.P. Meyers, J. Newman, J. Electrochem. Soc., 147 (2000) 99-110.

[16] J.P. Meyers, M. Doyle, R.M. Darling, J. Newman, J. Electrochem. Soc., 147 (2000) 2930-2940.

[17] C.R. Pals, J. Newman, J. Electrochem. Soc., 142 (1995) 3274-3281.

[18] C.R. Pals, J. Newman, J. Electrochem. Soc., 142 (1995) 3282-3288.

[19] L. Rao, J. Newman, J. Electrochem. Soc., 144 (1997) 2697-2704.

[20] K.E. Thomas, J. Newman, J. Electrochem. Soc., 150 (2003) A176-A192.

[21] D. Bernardi, E. Pawlikowski, J. Newman, J. Electrochem. Soc., 132 (1985) 5-12.

[22] P. Albertus, J. Christensen, J. Newman, J. Electrochem. Soc., 155 (2008) A48-A60.

[23] P. Albertus, J. Couts, V. Srinivasan, J. Newman, J. Power Sources, 183 (2008)

771-782.

[24] P. Albertus, J. Christensen, J. Newman, J. Electrochem. Soc., 156 (2009) A606-A618.

[25] T.F. Fuller, M. Doyle, J. Newman, J. Electrochem. Soc., 141 (1994) 982-990.

[26] T.F. Fuller, M. Doyle, J. Newman, J. Electrochem. Soc., 141 (1994) 1-10.

[27] P. Arora, M. Doyle, A.S. Gozdz, R.E. White, J. Newman, J. Power Sources, 88 (2000) 219-231. 
[28] J. Christensen, V. Srinivasan, J. Newman, J. Electrochem. Soc., 153 (2006) A560-A565.

[29] S.G. Stewart, V. Srinivasan, J. Newman, J. Electrochem. Soc., 155 (2008) A664-A671.

[30] M.W. Verbrugge, AIChE J., 41 (1995) 1550-1562.

[31] V. Ramadesigan, P.W.C. Northrop, S. De, S. Santhanagopalan, R.D. Braatz, V.R. Subramanian, J. Electrochem. Soc., 159 (2012) R31-R45.

[32] F.B. Hildebrand, Advanced Calculus for Applications, Second Edition, Prentice-Hall, 1976.

[33] O. Iliev, A. Latz, J. Zausch, S. Zhang, An Overview on the Usage of Some Model Reduction Approaches for Simulations of Li-ion Transport in Batteries, Berichte des Fraunhofer ITWM, 2012.

[34] H. Maleki, S. Al Hallaj, J.R. Selman, R.B. Dinwiddie, H. Wang, J. Electrochem. Soc., 146 (1999) 947-954.

[35] L. Song, J.W. Evans, J. Electrochem. Soc., 147 (2000) 2086-2095.

[36] G.G. Trost, V. Edwards, Electrochemical reaction engineering, in: J.J. Carberry, A. Varma (Eds.) Chemical reaction and reactor engineering, Marcel Dekker, Inc., New York, 1987. 
[37] W.B. Du, N.S. Xue, A.M. Sastry, J.R.R.A. Martins, W. Shyy, J. Electrochem. Soc., 160 (2013) A1187-A1193.

[38] K.E. Thomas, Dissertation, University of California, Berkeley, 2002.

[39] S. Stewart, Dissertation, University of California, Berkeley, Berkeley, 2007.

[40] S. Stewart, J. Newman, J. Electrochem. Soc., 155 (2008) A458-A463.

[41] C. Capiglia, Y. Saito, H. Kageyama, P. Mustarelli, T. Iwamoto, T. Tabuchi, H. Tukamoto, J. Power Sources, 81 (1999) 859-862.

[42] L.O. Valoen, J.N. Reimers, J. Electrochem. Soc., 152 (2005) A882-A891.

[43] A. Nyman, M. Behm, G. Lindbergh, Electrochim. Acta, 53 (2008) 6356-6365.

[44] T. Abe, H. Fukuda, Y. Iriyama, Z. Ogumi, J. Electrochem. Soc., 151 (2004) A1120-A1123.

[45] V. Srinivasan, C.Y. Wang, J. Electrochem. Soc., 150 (2003) A98-A106.

[46] K. Xu, J. Electrochem. Soc., 154 (2007) A162-A167.

[47] T.R. Jow, M.B. Marx, J.L. Allen, J. Electrochem. Soc., 159 (2012) A604-A612.

[48] W. Jost, Diffusion in Solids, Liquids, Gases, Academic Press, New York, 1960.

[49] H. Mehrer, Diffusion in Solids: Fundamentals, Methods, Materials, Diffusion-Controlled Processes, Springer, 2007.

[50] R.B. Bird, W.E. Stewart, E.N. Lightfoot, Transport Phenomena, John Wiley \& Sons, 2007. 
[51] K.J. Vetter, Electrochemical kinetics: theoretical and experimental aspects, Academic Press, 1967.

[52] W.J. Moore, Physical Chemistry, Prentice-Hall, 1999.

[53] V. Ramadesigan, V. Boovaragavan, J.C. Pirkle, V.R. Subramanian, J. Electrochem. Soc., 157 (2010) A854-A860.

[54] Y. Zeng, P. Albertus, R. Klein, N. Chaturvedi, A. Kojic, M.Z. Bazant, J. Christensen, J. Electrochem. Soc., 160 (2013) A1565-A1571.

[55] J.N. Reimers, J. Electrochem. Soc., 160 (2013) A811-A818.

[56] J.S. Newman, C.W. Tobias, J. Electrochem. Soc., 109 (1962) 1183-1191.

[57] J. Newman, W. Tiedemann, AIChE J., 21 (1975) 25-41.

[58] J.R. Dahn, S. Trussler, S. Dugas, D.J. Coyle, J.J. Dahn, J.C. Burns, J. Electrochem. Soc., 160 (2013) A251-A258.

[59] K.K. Patel, J.M. Paulsen, J. Desilvestro, J. Power Sources, 122 (2003) 144-152.

[60] P. Arora, Z.M. Zhang, Chem. Rev., 104 (2004) 4419-4462.

[61] R. Spotnitz, J. Franklin, J. Power Sources, 113 (2003) 81-100.

[62] A.J. Smith, J.C. Burns, X.M. Zhao, D.J. Xiong, J.R. Dahn, J. Electrochem. Soc., 158 (2011) A447-A452.

[63] P. Verma, P. Maire, P. Novak, Electrochim. Acta, 55 (2010) 6332-6341.

[64] M.N. Richard, J.R. Dahn, J. Electrochem. Soc., 146 (1999) 2068-2077. 
[65] M.N. Richard, J.R. Dahn, J. Electrochem. Soc., 146 (1999) 2078-2084.

[66] D.D. MacNeil, D. Larcher, J.R. Dahn, J. Electrochem. Soc., 146 (1999) 3596-3602.

[67] J. Vetter, P. Novak, M.R. Wagner, C. Veit, K.C. Moller, J.O. Besenhard, M. Winter, M. Wohlfahrt-Mehrens, C. Vogler, A. Hammouche, J. Power Sources, 147 (2005) 269-281.

[68] E.P. Roth, C.J. Orendorff, Electrochem. Soc. Interface, 21 (2012) 45-49.

[69] A.W. Golubkov, D. Fuchs, in: A. Thaler, D. Watzenig (Eds.) Automotive Battery Technology, Springer International Publishing, 2014, pp. 37-51.

[70] S.E. Sloop, J.B. Kerr, K. Kinoshita, J. Power Sources, 119 (2003) 330-337.

[71] P.G. Balakrishnan, R. Ramesh, T.P. Kumar, J. Power Sources, 155 (2006) 401-414.

[72] E.P. Roth, D.H. Doughty, J. Power Sources, 128 (2004) 308-318.

[73] C.J. Orendorff, Electrochem. Soc. Interface, 21 (2012) 61-65.

[74] M. Baginska, B.J. Blaiszik, R.J. Merriman, N.R. Sottos, J.S. Moore, S.R. White, Adv. Energy Mater., 2 (2012) 583-590.

[75] O.Y. Egorkina, A.M. Skundin, J. Solid State Electrochem., 2 (1998) 216-220.

[76] M. Guo, G. Sikha, R.E. White, J. Electrochem. Soc., 158 (2011) A122-A132. 
Table I. Design-adjustable parameters.

\begin{tabular}{lrr}
\hline Parameters & $\mathbf{L i}_{x} \mathbf{C}_{\mathbf{6}}(\mathbf{M C M B})$ & $\mathbf{L i}_{y} \mathbf{C o O}_{\mathbf{2}}$ \\
\hline Thickness of electrode $(\mu \mathrm{m})$ & 96 & 60 \\
Thickness of current collector $(\mu \mathrm{m})$ & 10 & 10 \\
Initial stoichiometric value $\left(x_{\mathrm{o}}\right.$ or $\left.y_{\mathrm{o}}\right)$ & 0.8 & 0.6 \\
Particle radius $(\mu \mathrm{m})$ & 8 & 5 \\
Volume fraction of electrolyte, $\varepsilon$ & 0.4 & 0.36 \\
Volume fraction of inert filler, $\varepsilon \mathrm{f}$ & 0.064 & 0.106 \\
\hline Parameters & & Value \\
\hline Ambient air temperature $(\mathrm{K}), T_{a}$ & & 298 \\
Volume fraction of electrolyte in separator & & 0.4 \\
Separator thickness $(\mu \mathrm{m})$ & & 25 \\
Grid resistance $\left(\Omega \cdot \mathrm{m}^{2}\right), R G$ & & $0.0008^{\mathrm{a}}$ \\
Grid resistance outside the cell sandwich $\left(\Omega \cdot \mathrm{m}^{2}\right), R G_{\mathrm{ext}}$ & & $0.0002^{\mathrm{a}}$ \\
Mass of the whole cell $\left(\mathrm{kg} / \mathrm{m}^{2}\right), \quad M$ & & 0.4932 \\
Heat capacity of system $(\mathrm{J} / \mathrm{kg} \cdot \mathrm{K}), C_{p}$ & $1000^{\mathrm{b}}$ \\
Heat-transfer coefficient $\left(\mathrm{W} / \mathrm{m}^{2} \cdot \mathrm{K}\right), h$ & $0.368^{\mathrm{c}}$ \\
\hline
\end{tabular}

a: ref. 36; b: ref. 4, 34; c: ref. 35

Table II. Physical property values at $298 \mathrm{~K}$.

\begin{tabular}{lrr}
\hline Parameters & $\mathbf{L i}_{x} \mathbf{C}_{\mathbf{6}}(\mathbf{M C M B})$ & $\mathbf{L i}_{\mathbf{y}} \mathbf{C o O}_{\mathbf{2}}$ \\
\hline Matrix conductivity $(\mathrm{S} / \mathrm{m}), \sigma$ & $100^{\mathrm{a}}$ & $0.5^{\mathrm{a}}$ \\
Film resistance $\left(\Omega \cdot \mathrm{m}^{2}\right), R_{\mathrm{f}}$ & $0.0035^{\mathrm{b}}$ & 0 \\
Coulombic capacity $(\mathrm{mAh} / \mathrm{g})$ & 372 & 148 \\
Maximum $\mathrm{Li}^{+}$concentration $\left(\mathrm{mol} / \mathrm{m}^{3}\right), c \mathrm{t}$ & $2.86 \times 10^{4}$ & $2.55 \times 10^{4}$ \\
Density of active material $\left(\mathrm{kg} / \mathrm{m}^{3}\right)$ & $1800^{\mathrm{c}}$ & $5010^{\mathrm{c}}$ \\
Diffusion coefficient in solid $\left(\mathrm{m}^{2} / \mathrm{s}\right), D_{\mathrm{s}}$ & $7 \times 10^{-14 \mathrm{~d}}$ & $3.0 \times 10^{-14 \mathrm{~d}}$ \\
Transfer coefficient $\alpha_{\mathrm{a}}, \alpha_{\mathrm{c}}$ & 0.5 & 0.5 \\
Reaction rate constant $\left(\mathrm{m}^{2.5} \mathrm{~mol}^{-0.5} \mathrm{~s}^{-1}\right), k$ & $3.0 \times 10^{-9 \mathrm{a}}$ & $3.0 \times 10^{-9 \mathrm{a}}$ \\
Density of current collector $\left(\mathrm{kg} / \mathrm{m}^{3}\right)$ & $8954^{\mathrm{c}}$ & $2707^{\mathrm{c}}$ \\
\hline
\end{tabular}

a: assumed to be large; b: ref. 24; c: ref. 37; d: assumed 
Table III. Parameters for the electrolyte (1 M LiPF6 in 1:1 EC/DMC) *.

\begin{tabular}{lc}
\hline Parameters & Value \\
\hline Density $\left(\mathrm{kg} / \mathrm{m}^{3}\right)$ & 1324 \\
Salt concentration $\left(\mathrm{mol} / \mathrm{m}^{3}\right), c$ & 1000 \\
Salt diffusion coefficient $\left(\mathrm{m}^{2} / \mathrm{s}\right), D$ & $5.34 \times 10^{-10} \varepsilon^{1.5} \exp \left(\frac{-0.65 c}{1000}\right)$ \\
Lithium ion transference number: $t_{+}{ }^{0}$ & 0.4 \\
Ionic conductivity of liquid solution & $\varepsilon^{1.5}\left[0.0911+\frac{1.9101 c}{1000}-1.052\left(\frac{c}{1000}\right)^{2}+0.1554\left(\frac{c}{1000}\right)^{x}\right]$ \\
$(\mathrm{S} / \mathrm{m}), \kappa$ & \\
Thermodynamic factor: & 1 \\
$\left(1+d \ln f_{ \pm} / d \ln c\right)$ & \\
\hline
\end{tabular}

* use the property put in the Dualfoil program directly

Table IV. Activation energy values*.

\begin{tabular}{lrr}
\hline Activation energy & Value $(\boldsymbol{E a} / \boldsymbol{R}$, units of K) & Value $(\mathbf{J} / \mathbf{m o l})$ \\
\hline Solid-state diffusion, negative & 200 & 1663 \\
Solid-state diffusion, positive & 900 & 7483 \\
Electrolyte conductivity $(\kappa)$ & 1690 & 13756 \\
Electrolyte diffusion $(D)$ & 2000 & 16628 \\
Negative kinetics & 1800 & 14965 \\
Positive kinetics & 1800 & 14965 \\
Film resistance of anode & -1800 & 14965 \\
Film resistance of cathode & -1800 & 14965 \\
\hline
\end{tabular}

*assumed based on ref. 48-52 
Table V. Equations used in the Dualfoil model.

\begin{tabular}{lc}
\hline Equation description & Equation \\
\hline Electrolyte material balance & $\varepsilon_{2} \frac{\partial c}{\partial t}=\nabla \cdot\left(\varepsilon_{2} D \nabla c\right)-\nabla \cdot\left(\frac{i_{2}\left(1-t_{+}^{0}\right)}{F}\right)$ \\
Intercalant material balance & $\frac{\partial c_{\mathrm{s}}}{\partial t}=\frac{1}{r^{2}} \frac{\partial}{\partial r}\left(D_{\mathrm{s}} r^{2} \frac{\partial c_{\mathrm{s}}}{\partial r}\right)$ \\
Liquid-phase Ohm's law & $i_{2}=-\kappa \nabla \Phi_{2}+\frac{2 \kappa R T}{F}\left(1-t_{+}^{0}\right) \nabla \ln \left(f_{ \pm} c\right)$ \\
Solid-phase Ohm's law & $i_{1}=-\sigma \nabla \Phi_{1}$ \\
Butler-Volmer kinetics & $i=j F=i_{0}\left[\exp \left(\frac{\alpha_{\mathrm{a}} F}{R T} \eta_{\mathrm{s}}\right)-\exp \left(-\frac{\alpha_{\mathrm{c}} F}{R T} \eta_{\mathrm{s}}\right)\right] /$ denominator \\
Exchange current density & $i_{0}=F k c^{\alpha_{\mathrm{a}}}\left(c_{\mathrm{t}}-c_{\mathrm{S}}\right)^{\alpha_{c}} C_{\mathrm{S}}{ }^{\alpha_{\mathrm{a}}}$ \\
Charge conservation & $\nabla \cdot i_{2}=a F j$ \\
\hline
\end{tabular}




\section{Figure captions}

Fig. 1. Simulation example of current and temperature-rise behavior versus discharge capacity for comparison of the three numerical modes: a. Superposition method

for constant $D_{\mathrm{s}} ; E a / R$ for negative and positive $D_{\mathrm{s}}$ is 0 . b. Superposition method for variable negative and positive $D_{\mathrm{s}} ; E a / R$ for negative and positive $D_{\mathrm{s}}$ is 200 and $900 \mathrm{~K}$, respectively. c. Finite-difference method for variable negative and positive $D_{s} ; E a / R$ for negative and positive $D_{\text {s }}$ is 200 and $900 \mathrm{~K}$, respectively.

Fig. 2. (a) Comparison of current and temperature simulation results versus time for case I and case II. (b) Comparison of cell potential and temperature simulation results versus utilization of positive material [calculated by $(y-0.6) / 0.4$ ]. Case I is the base case, and solution diffusivity $(D)$ is dependent on temperature with an activation energy $(E a)$ of $16.6 \mathrm{~kJ} / \mathrm{mol}$. Case II is the situation that $D$ is independent of temperature, keeping the value at 298 K. Similar information is plotted in Figure a and b to show how it appears with different abscissas.

Fig. 3. (a) and (b) Simulated solution concentration profiles for case I and case II in different depths of the cell. (c) and (d) Simulated solid surface-concentration profiles for case I and case II in different depths of the $\mathrm{Li}_{y} \mathrm{CoO}_{2}$ positive electrode. (e) and (f) Simulated solution-solid interface transfer current profiles for case I and case II in different depths of the $\mathrm{Li}_{y} \mathrm{CoO}_{2}$ positive electrode. 
Fig. 4. (a) Simulated current and temperature results for different porosities of positive electrode. (b) Simulated current and temperature results for different Bruggeman exponents of positive electrode (Exbrug3).

Fig. 5. (a) Simulated current and temperature results for different $D_{\mathrm{s}, \mathrm{p}}$ (b) Simulated current and temperature results for different radius of $\mathrm{Li}_{y} \mathrm{CoO}_{2}$ particles. (c) Simulated relative current-peak areas of different combinations of $D_{\mathrm{s}, \mathrm{p}}$ and $r_{\mathrm{p}}$. (Solid circles' area shows relative size of corresponding peak area qualitatively, and open circles mean no peak for current. The dashed line is the boundary of peak and no peak.)

Fig. 6. Simulated current and temperature- rise behavior for different heat-transfer conditions.

Fig. 7. Simulated current and temperature curves versus time for $R_{\text {load }}=0.0002$ $\Omega \cdot \mathrm{m}^{2}$ with and without shut-down separator, $h=0.368 \mathrm{~W} / \mathrm{m}^{2} \cdot \mathrm{K}$.

Fig. 8. The open-circuit potential and $d U / d T$ profiles for $\mathrm{MCMB}\left(\mathrm{Li}_{x} \mathrm{C}_{6}\right)$ and $\mathrm{Li}_{y} \mathrm{CoO}_{2}$ electrode $[38,75,76]$. 


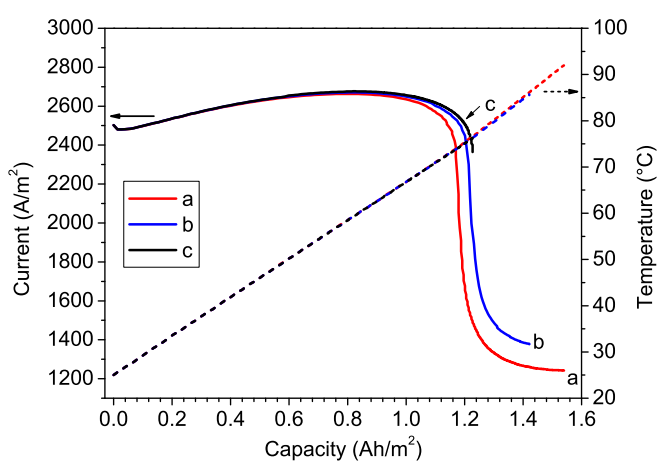




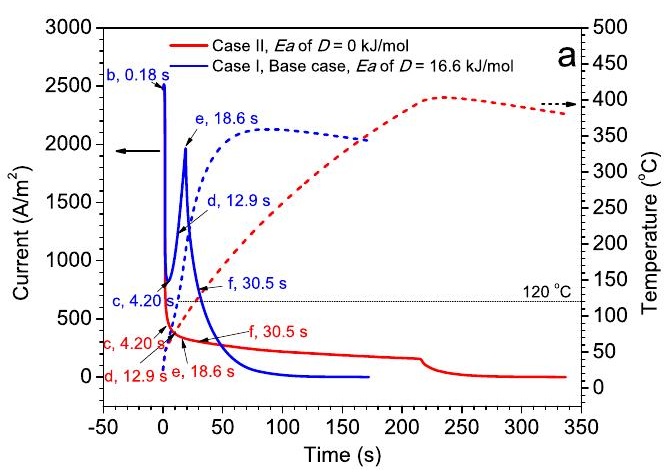




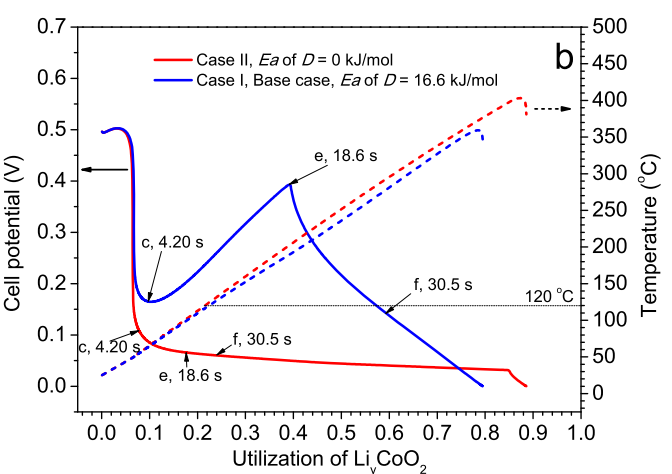



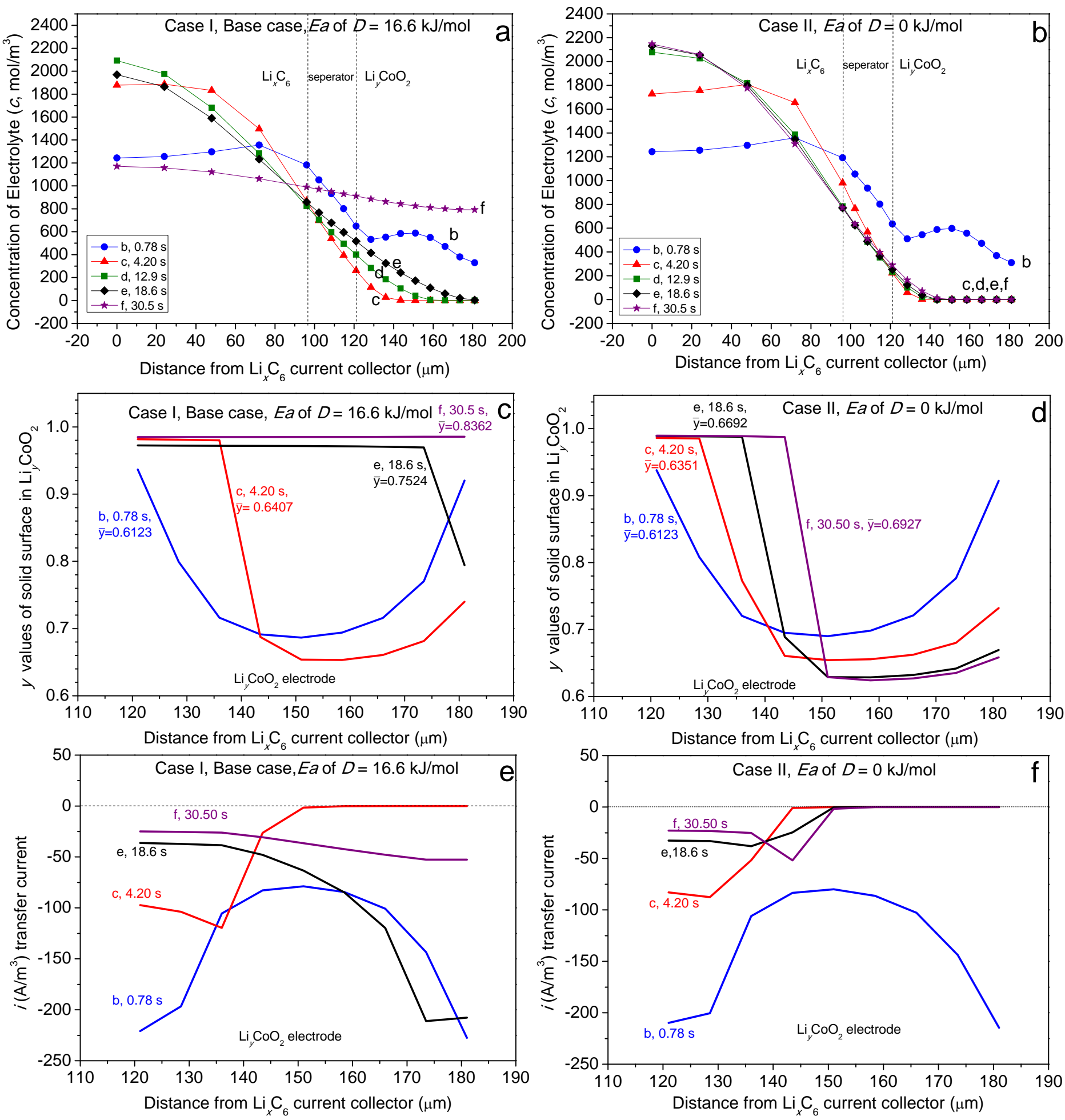


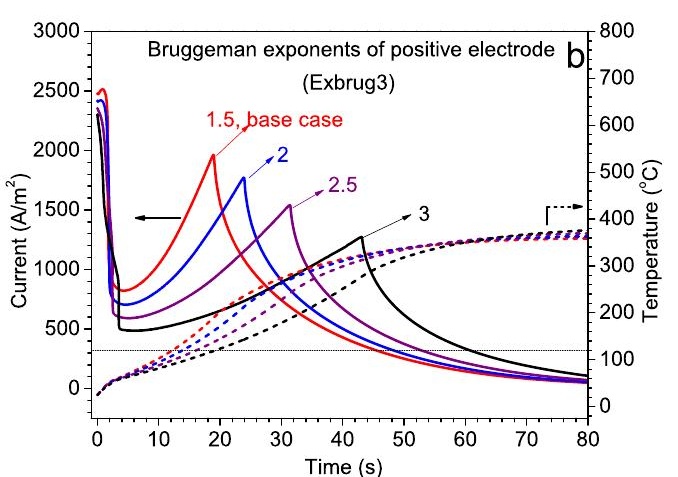




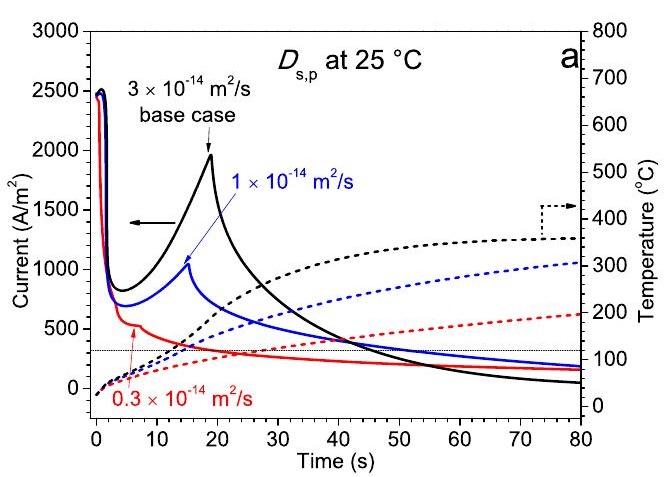




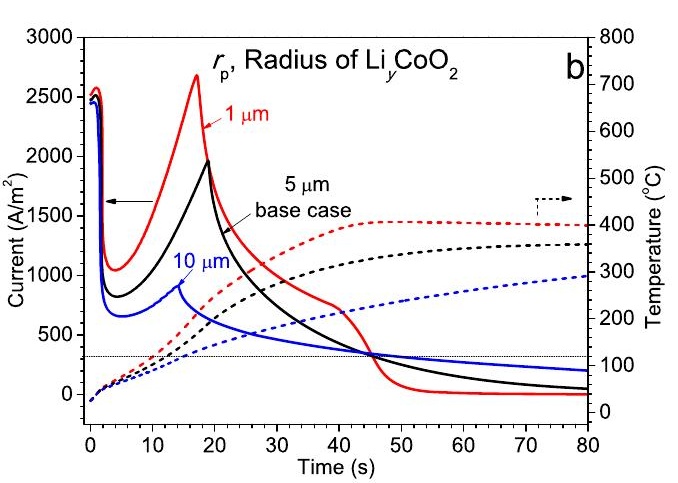




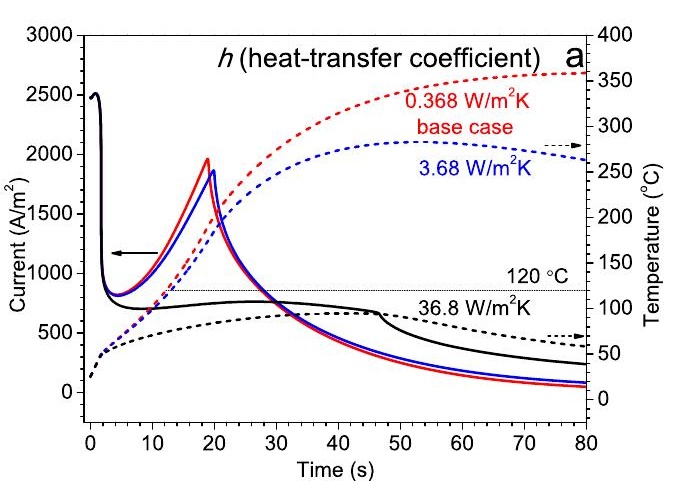




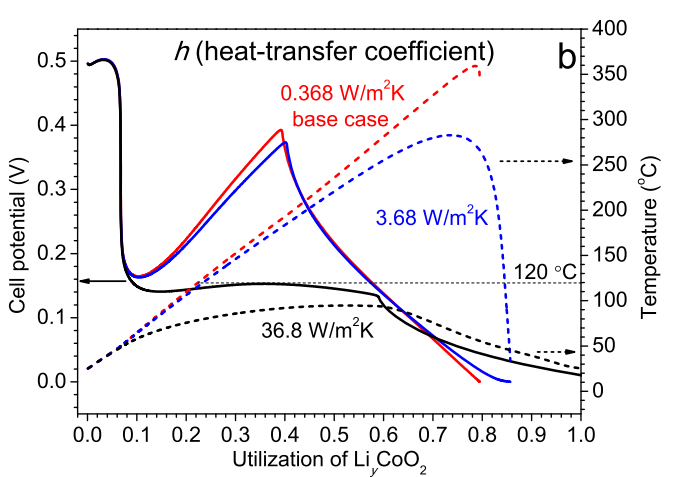




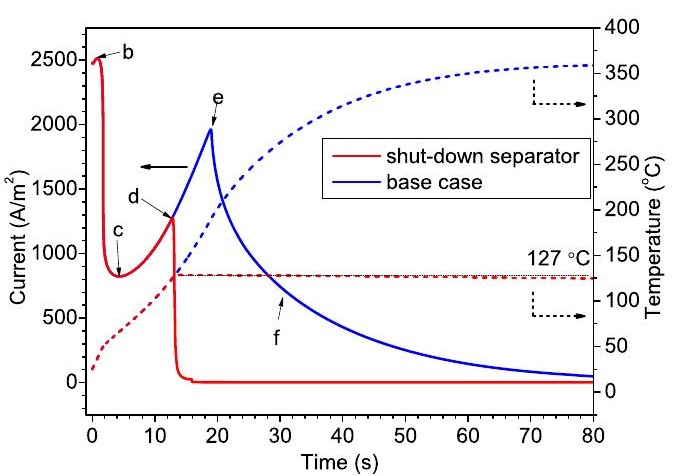



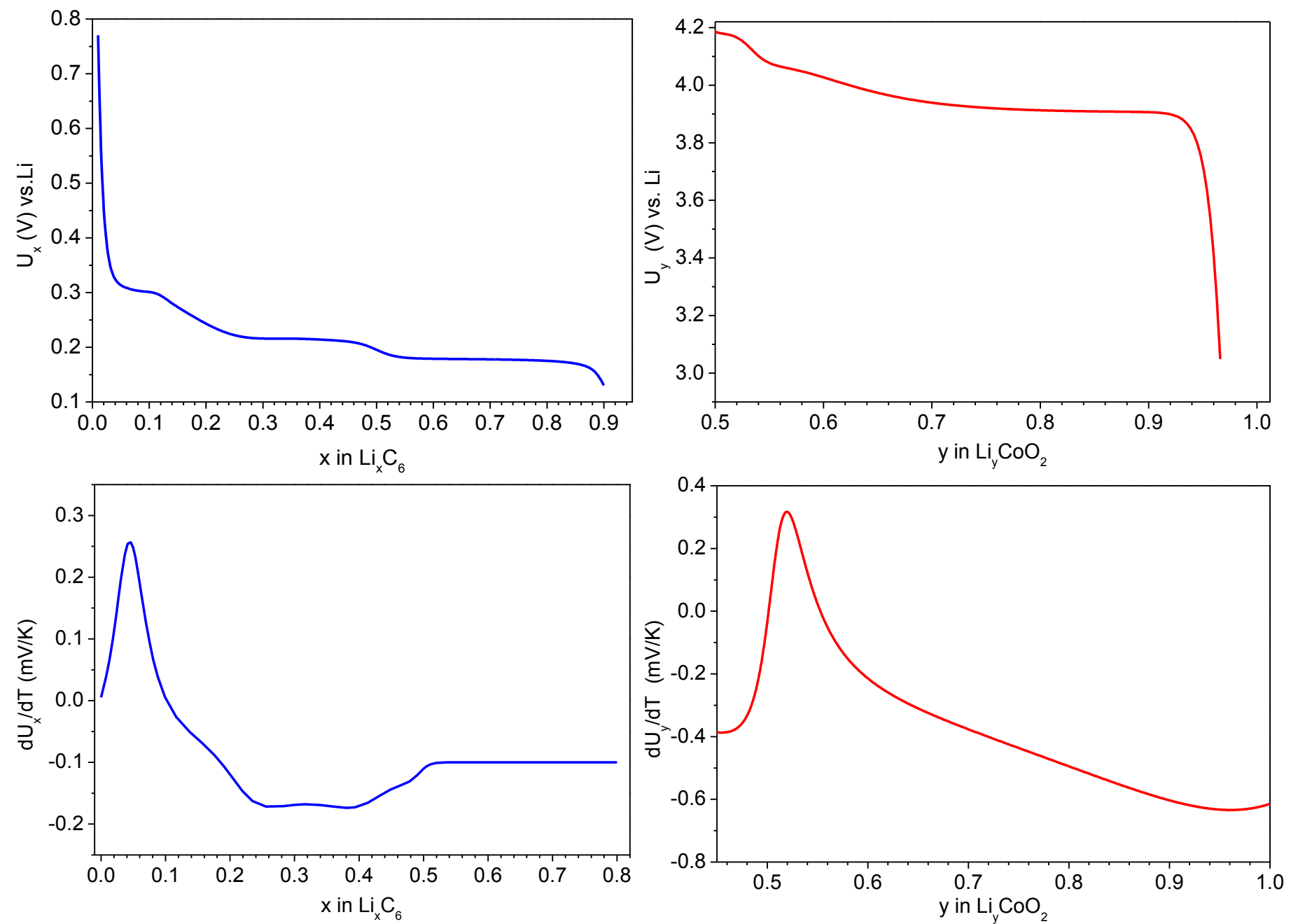